\title{
0 processo inflacionário e o consumo de vegetais e alimentos industrializados no Brasil: aspectos econômicos, climáticos e do comportamento do consumidor
}

\author{
Diogo Rógora Kawano \\ Bruno Rógora Kawano ${ }^{2}$ \\ Dieisson Pivoto ${ }^{3}$ \\ Leandro Leonardo Batista ${ }^{4}$
}

\begin{abstract}
RESUMO
Com o acirramento da competitividade, as tecnologias relacionadas à inteligência de mercado e seus processos tornaram-se fundamentais para que as empresas se mantenham no mercado, como, por exemplo, por meio de informações contínuas de inflação e do comportamento de compra dos consumidores. Este estudo identificou os fatores que mais impactaram na alta de preço dos cinco vegetais que apresentaram maior inflação no primeiro semestre de 2013, bem como apresenta as dez categorias de alimentos industrializados que proporcionaram maior queda em volume consumido, elencando possíveis fatores para o desempenho negativo desses produtos. Para tanto, foi realizada uma pesquisa explicativa, na forma de avaliação quantitativa e qualitativa, com base nos dados do Índice de Preços ao Consumidor Amplo e de informações de painel de consumo de 8.200 lares brasileiros. Os resultados apontaram que a retração no consumo não se deu de forma homogênea nas classes socioeconômicas, o qual variou consoante especificidades em cada uma das categorias. Conclui-se que outros fatores, além do aumento de preço, exerceram um papel relevante na retração de consumo, tais como mudanças atreladas à busca por produtos com maior valor agregado e praticidade.
\end{abstract}

Palavras-chave: Pesquisa de mercado. Comportamento do consumidor. Inflação. Varejo de alimentos.

\section{INTRODUÇÃO}

O primeiro semestre de 2013 destacou-se na esfera econômica pelos elevados índices de inflação, cujo valor acumulado de julho de 2012 a junho de 2013, segundo o Índice de Preços ao Consumidor Amplo (IPCA), chegou a 6,70\%, acima do teto estabelecido pelo governo federal, de 6,50\%. Nesse sentido, a alta de preços verificada pelo consumidor se deu nas diversas categorias de produtos e serviços.

${ }^{1}$ Mestrando em Ciências da Comunicação, em comportamento do consumidor na Universidade de São Paulo, ECA-USP - drkawano@gmail.com

2Doutorando em Engenharia Elétrica na Escola Politécnica, Universidade de São Paulo - USP -brkawano@gmail.com

${ }^{3}$ Mestre em Agronegócios. Universidade Federal do Rio Grande do Sul - dieissonpivoto@gmail.com

${ }^{4}$ Professor Doutor em Comunicação Social - University of North Carolina, docente da Escola de Comunicações e Artes da USP - ECA-USP - leleba@usp.br 
No centro de tal discussão, alguns itens merecem destaque especial, sobretudo aqueles pertencentes à cesta de alimentos. De fato, a referida cesta foi a única que sofreu retração de volume consumido no primeiro semestre de 2013, quando comparada ao mesmo período de 2012, conforme dados auditados pela empresa de pesquisa Kantar Worldpanel (informação pessoal ${ }^{7}$ ). Enquanto o consumo dos itens referentes à cesta de limpeza, bebidas e perfumaria cresceu 3,8\%, 2,8\% e 0,4\%, respectivamente, a cesta de alimentos fechou o semestre com retração de $0,2 \%$.

Ainda sim, embora haja estudos que discutam a produção e comercialização de alimentos, na maior parte das vezes, eles abordam as chamadas commodities (NEPA, 2009), havendo, na literatura científica, poucos trabalhos que tratem da variação de consumo de alimentos industrializados de natureza diversa (como, por exemplo, leite em pó, pratos prontos congelados e massas instantâneas) sob um método de coleta unificado. Por fim, identificar de forma conjunta onde houve maior ou menor variação no consumo, dentro das classes socioeconômicas, exprime o problema discutido e analisado neste estudo, a fim de fornecer uma compreensão a respeito dos aspectos que atuaram sobre o consumo de determinadas categorias no primeiro semestre de 2013.

Por conseguinte, esta pesquisa identificou os fatores que mais impactaram na alta de preço dos cinco vegetais que apresentaram maior inflação no primeiro semestre de 2013, bem como apresenta as dez categorias de alimentos industrializados que tiveram maior queda em volume consumido no mesmo período considerado, de forma a elencar possíveis fatores para o desempenho negativo de tais produtos.

A reflexão sobre a dinâmica desses produtos no mercado permite uma compreensão mais detalhada tanto dos fatores determinantes para a alteração no consumo como do processo inflacionário dos alimentos, cujos aspectos atuam desde o começo da cadeia produtiva até a comercialização dos produtos no varejo.

No âmbito da produção, este estudo contribui para entender em que medida fatores climáticos ou outros aspectos ligados ao cultivo de vegetais ou matérias-primas impactam no aumento de preço, o qual desencadeará um aumento no valor final do produto para o consumidor.

Para o varejo, esse entedimento justifica-se em razão da necessidade de o setor se programar para evitar rápidos aumentos dos preços, aspectos que podem atuar na contratualização da produção, gestão de estoques para produtos não perecíveis, identificação de público-alvo mais impactado e direcionamento de ações que visem à atenuação negativa propiciada pelas oscilações nos preços dos alimentos.

\section{DINÂMICAS DE PREÇOS E O PROCESSO DECISÓRIO NA COMPRA DE PRODUTOS DO SETOR DE ALIMENTOS}

O modelo de oferta e demanda busca descrever o comportamento dos preços em uma economia de mercado. É uma ferramenta útil para a compreensão da dinâmica de preço nas diferentes cadeias agroindustriais $^{8}$. As curvas de demanda são uma derivação baseada na teoria do consumidor individual, utilizando-se de duas aproximações (a teoria de utilidade e das curvas de indiferença). A demanda de mercado é conceituada como o somatório das demandas individuais (ARBAGE, 2006).

De forma geral, a variação nos preços dos produtos agroindustriais não causa uma variação tão acentuada em sua demanda. Com isso, nota-se que, no caso de escassez dos produtos agroindustriais, os preços precisam elevar muito para limitar o consumo. Conforme expressa Azevedo (2010), a quantidade demandada pelos produtos agroindustriais não varia significativamente em relação ao preço quando comparado à variação dos demais produtos.

A elasticidade preço da demanda mede a variação percentual na quantidade demandada quando ocorre a variação de $1 \%$ no preço de um bem ou serviço (PINDYCK; RUBINFELD, 2010). A demanda por um produto poderá ser elástica (sensível), inelástica (insensível) ou unitária (a variação da quantidade se dará na mesma proporção que a variação do preço).

Alguns fatores são deslocadores da curva de demanda, como o preço de produtos substitutos, os preços de produtos complementares, a renda dos consumidores, as expectativas futuras quanto aos preços futuros, entre outros. No que diz respeito à disponibilidade de produtos substitutos, considera-se que, quanto mais substitutos existirem no mercado, maior será a possibilidade de um produto ter a demanda elástica

${ }^{6} 0$ IPCA é calculado pelo IBGE desde 1980, e refere-se às famílias com rendimento monetário de um a quarenta salários mínimos, qualquer que seja a fonte, e abrange nove regiões metropolitanas do país, além do município de Goiânia e de Brasília" (IBGE, 2013a, p. 6), sendo composto pelos grupos de análise: alimentos e bebidas, habitação, artigos de residência, vestuário, transportes, saúde de cuidados especiais, despesas pessoais, educação, comunicação.

${ }^{7}$ ANDRADE, Carolina. Variação de consumo na cesta de alimentos nas classes socioeconômicas: Kantar Worldpanel Brasil. Mensagem recebida por < drkawano@gmail.com > em 12 de agosto de 2013.

${ }^{8}$ Produtos agroindustriais englobam produtos de origem agrícola, pecuária ou extrativista destinados à alimentação humana com ou sem processamento. 
(PINDYCK; RUBINFELD, 2010).

Um aspecto que cabe ressaltar é que, no Brasil e em países onde a renda per capita é baixa e a distribuição de renda é concentrada, essa característica da demanda por produtos agroindustriais é menos acentuada (AZEVEDO, 2010). Isso ocorre em virtude de uma parcela acentuada da população não possuir renda suficiente para a aquisição mínima de alimentos; pode acontecer que uma elevação nos preços retire consumidores do mercado, reduzindo, assim, a quantidade demandada. As principais variáveis que impactam na demanda são o tamanho da população, a renda per capita e a distribuição de renda.

Por outro lado, a oferta de produtos agroindustriais apresenta um comportamento de maior instabilidade por diversos fatores, como, por exemplo, a sazonalidade da produção, que impacta na oferta desses produtos ao longo do ano, tendo reflexos nos índices de inflação. Outro aspecto que torna a oferta de produtos agrícolas e agroindustriais instáveis é o caráter biológico da produção. A produção agropecuária é dependente das condições climáticas e de variáveis que são de difícil controle quando comparada à produção industrial.

Alguns fatores são responsáveis por deslocar a curva de oferta dos produtos agroindustriais, como a mudança no nível tecnológico, as condições climáticas que afetam os níveis de produção (escassez de precipitações, geadas, altas ou baixas temperaturas), os preços de produtos que concorrem pelos mesmos fatores de produção na fazenda, as expectativas futuras sobre as condições de mercado (oferta e demanda, preços de bens complementares e substitutos).

O preço de um bem ou serviço é a principal informação disponível para a tomada de decisões; assim sendo, os compradores dispostos a pagar o menor preço possível e os produtores buscando receber o maior preço possível. Além da dinâmica de formação de preços, conferida pelo modelo de oferta e demanda, o varejo tem um papel relevante nas cadeias agroindustriais. 0 varejo é o elo da cadeia produtiva que tem contato direto com o consumidor final, sendo muitas das estratégias adotadas pelo setor as que impactam na decisão de compra do consumidor.

Por envolver os mais diversos âmbitos da vivência humana (individual ou social, pessoal ou profissional), a dinâmica da tomada de decisão apresenta complexidade e variedade de processos que se dão conforme a natureza do problema abordado (SOLOMON, 2008). Ademais, inclui desde processos rápidos, paralelos e julgamentos livres de esforço cognitivo até decisões de caráter de maior envolvimento, que exigem uma avaliação mais racional por meio de busca e escolha de alternativas (KAHNEMAN, 2012).

Nesse sentido, no presente trabalho, torna-se pertinente uma discussão que permita um entendimento de quais são e de como se configuram as etapas de um processo decisório de forma ampla. Assim, os aspectos basilares aqui apresentados partirão da abordagem voltada ao comportamento do consumidor, com base em Solomon (2008).

O reconhecimento do problema é o primeiro estágio do processo, podendo ser simples ou complexo, o qual surge a partir de um gap que se forma entre o estado real (como a ausência do produto) e o estado ideal (presença do produto). A etapa subsequente contempla a busca de informações que, no caso deste trabalho, pode verificar-se de forma passiva (exposição dos consumidores a conteúdos e matérias jornalísticas que informam elevação dos preços dos produtos) ou de forma mais ativa (direcionamento para a fase de avaliação de alternativas). Por fim, há a finalização com a escolha do produto a ser adquirido e seu posterior uso. A experiência de uso trará um importante feedback ao consumidor, que se utilizará da experiência tida com o produto para as decisões futuras, que gerarão repetição ou abandono do comportamento realizado.

\subsection{Trabalhos similares de identificação do impacto da inflação sobre o consumo de alimentos}

Trabalhos relacionados à temática de inflação e sua influência no consumo de alimentos são apresentados no Quadro 1. Em estudo da FGV (2008) e FAO (2008) a respeito da contribuição dos preços de alimentos no índice da inflação, conclui-se que o aumento de preços da referida categoria exerceu pressão negativa no consumo de alimentos, principalmente nos países em desenvolvimento, especialmente na China. Esse fato pode ser observado na Figura 1. 
Figura 1 - Contribuição dos alimentos para a alta de inflação em diferentes países

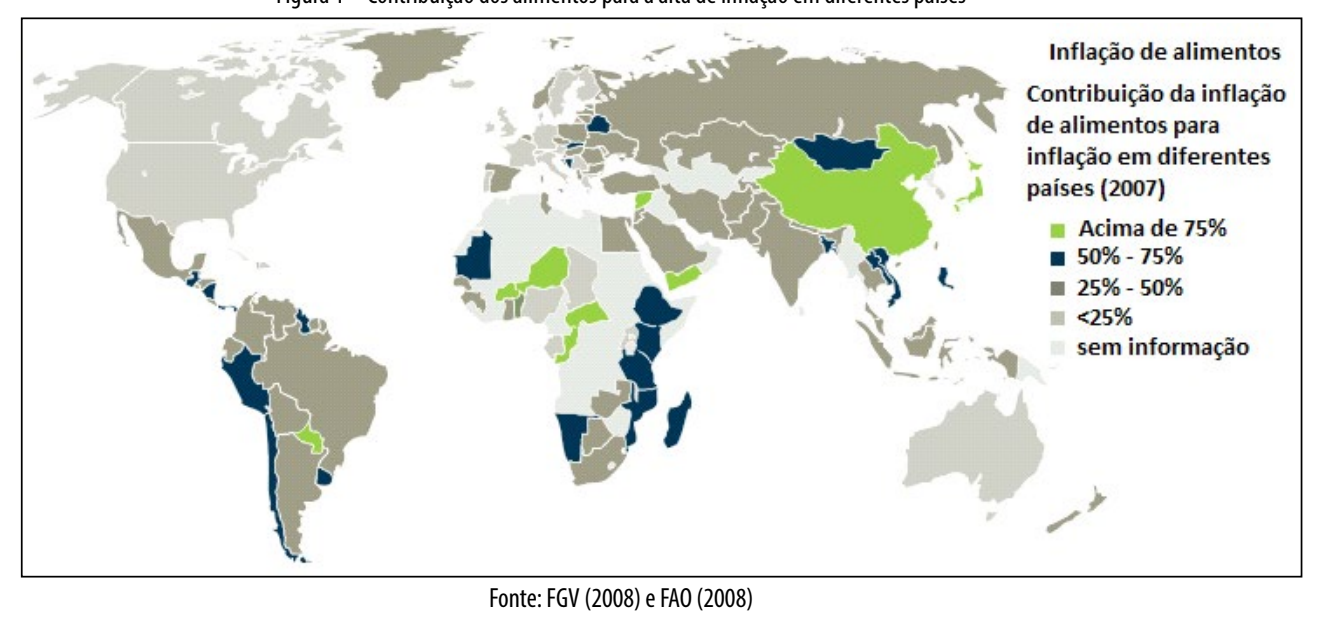

Em estudo do Núcleo de Estudos e Pesquisas em Alimentação (NEPA, 2009), a conclusão sobre o aumento da inflação acerca do consumo de alimentos foi semelhante ao que se observou no estudo da Fundação Getúlio Vargas (FGV, 2008). Sendo assim, concluiu-se que o aumento de preços de alimentos, e até do preço do petróleo, acarretou uma maior vulnerabilidade de pessoas pertencentes às classes socioeconômicas mais baixas, influenciando diretamente no consumido reduzido de alimentos.

Já os estudos de Martinez e Cerqueira (2013), e de Maluf e Speranza (2013), a propósito dos fatores que contribuem para o aumento da inflação, inclusive sobre a inflação do setor de alimentos no Brasil, obtiveram conclusões semelhantes. Seus resultados indicaram também que aumentos nos níveis de preços dos alimentos colaboraram para o aumento da inflação no país nos períodos analisados e, dessa forma, influenciaram na redução do consumo de alimentos, principalmente por famílias pertencentes às classes socioeconômicas com menor renda.

Quadro 1 - Pesquisas que relacionam inflação com o consumo de alimentos

\begin{tabular}{|c|c|c|c|c|}
\hline Ano & Autor & Objetivo & Resultado & $\begin{array}{c}\text { Principais fatores de impacto } \\
\text { utilizados }\end{array}$ \\
\hline 2008 & FGV PROJETOS E FAO & $\begin{array}{l}\text { Analisar a contribuição } \\
\text { do preço dos alimentos } \\
\text { para a inflação em } \\
\text { diferentes países. }\end{array}$ & $\begin{array}{l}\text { Houve consequências econômicas } \\
\text { e sociais negativas principalmente } \\
\text { em regiões carentes no mundo, } \\
\text { com destaque para a China, onde a } \\
\text { inflação de alimentos foi responsável } \\
\text { por mais de } 75 \% \text { do aumento do } \\
\text { custo de vida. }\end{array}$ & $\begin{array}{c}\text { Índice de pobreza e renda das } \\
\text { camadas mais pobres dos países } \\
\text { analisados. }\end{array}$ \\
\hline 2009 & $\begin{array}{l}\text { Núcleo de Estudos e } \\
\text { Pesquisas em Alimen- } \\
\text { tação (NEPA) Unicamp }\end{array}$ & $\begin{array}{l}\text { Avaliar a vulnerabilidade } \\
\text { de classes de pessoas } \\
\text { com renda menor ao } \\
\text { preço de alimentos. }\end{array}$ & $\begin{array}{l}\text { Constatação de que os extratos de } \\
\text { pessoas com renda menor estão mais } \\
\text { sujeitos a sofrer as consequências } \\
\text { negativas de aumento de preço de } \\
\text { alimentos. }\end{array}$ & $\begin{array}{l}\text { Condições econômicas de outros } \\
\text { países, bem como variação do } \\
\text { preço de commodities alimentares } \\
\text { e petróleo. }\end{array}$ \\
\hline 2013 & $\begin{array}{l}\text { MARTINEZ e CER- } \\
\text { QUEIRA }\end{array}$ & $\begin{array}{c}\text { Analisar determinantes } \\
\text { da estrutura da inflação } \\
\text { no Brasil. }\end{array}$ & $\begin{array}{l}0 \text { setor de Alimentos e Bebidas não } \\
\text { comercializáveis exerceu grande } \\
\text { influência sobre a alta da inflação em } \\
\text { 2001, 2002, } 2004 \text { e } 2005 \text {. }\end{array}$ & $\begin{array}{l}\text { Foram avaliados níveis de preço } \\
\text { e inflação de alimentos, como } \\
\text { feijão, legumes, verduras, frutas, } \\
\text { pescados e ovos. }\end{array}$ \\
\hline 2013 & MALUF e SPERANZA & $\begin{array}{l}\text { Analisar fatores prepon- } \\
\text { derantes da inflação de } \\
\text { alimentos no Brasil. }\end{array}$ & $\begin{array}{l}\text { Aumento de preços dos alimentos } \\
\text { influenciou em menor consumo em } \\
\text { quantidade e qualidade de alimentos } \\
\text { ingeridos pelas famílias. } 0 \text { estudo } \\
\text { indicou também que essa redução } \\
\text { no consumo evidenciou-se mais nas } \\
\text { famílias rurais de baixa renda. }\end{array}$ & $\begin{array}{c}\text { Os fatores analisados foram o } \\
\text { índice de inflação e preço de } \\
\text { alimentos consumidos pelas } \\
\text { famílias brasileiras, com destaque } \\
\text { às famílias residentes em zonas } \\
\text { rurais. }\end{array}$ \\
\hline
\end{tabular}

Fonte: Elaborado pelos autores (2014) 


\section{PROCEDIMENTOS METODOLÓGICOS}

Quanto aos seus objetivos, esta é uma pesquisa explicativa, na medida em que busca apontar e explicar as razões atreladas ao aumento de preço e à redução de consumo de alimentos industrializados. Ademais, no que tange à forma de abordagem de avaliação do trabalho, trata-se de uma pesquisa quantitativa, realizada com base em dados inflacionários e de consumo nas classes socioeconômicas.

Configurou-se em uma pesquisa com características avaliativas distintas, pois adotou avaliações quantitativas e qualitativas (MARTINS; THEÓPHILO, 2009). 0 tempo em que se analisaram dados estatísticos exigiu análises e explicações decorrentes das informações expressas nos dados e números coletados.

Para a realização desta pesquisa, a coleta dos dados para as análises contemplou duas etapas. A primeira delas buscou explorar os cinco alimentos que registraram as maiores altas de preço no primeiro semestre de 2013, de acordo com o IPCA/IBGE. São eles, em ordem decrescente de aumento de preços: batata inglesa, cebola, cenoura, tomate e feijão carioca (rajado). Os citados produtos igualmente se destacaram na mídia pelos aumentos mensais de preço no período analisado. Essa análise utilizou levantamento bibliográfico e de informações relacionadas ao contexto econômico das cadeias produtivas dos alimentos, de forma a auxiliar na busca de explicações para a elevação dos preços.

A segunda parte desta pesquisa foi iniciada por meio da análise de uma série de dados cedidos pela empresa Kantar Worldpanel (informação pessoal ${ }^{9}$ ), especialmente para a realização deste artigo, que contém as variações percentuais em volume de consumo de categorias relativas às cestas de alimentos no primeiro semestre de 2013 em relação ao primeiro semestre de 2012. Ademais, essas variações percentuais em volume das categorias foram aprofundadas mediante segmentação do consumo dos itens nas classes $A B$, C e DE, segundo a metodologia de classificação socioeconômica do critério Brasil.

A forma de coleta dos dados da Kantar Worldpanel ocorre por meio da realização de um painel de domicílios, nos quais há a verificação semanal dos itens comprados pelos lares. A amostra de 8.200 domicílios é feita com base no número de domicílios aferidos pelo IBGE, mas restringindo-se às cidades com dez mil habitantes ou mais ${ }^{10}$.

Depois disso, selecionaram-se as dez categorias de alimentos, em que foram verificadas as maiores variações de consumo em volume, considerando o total consumido por todas as classes socioeconômicas sugeridas. As categorias selecionadas foram: polpa e purê de tomate, leite em pó, pratos prontos congelados, bebida à base de soja (BBS), batata congelada, cereal tradicional, massa instantânea, sobremesa em pó, suco concentrado, hambúrguer. Para as categorias mencionadas, realizou-se uma análise sobre os motivos das reduções no consumo em volume no período considerado e as relações das categorias com as classes socioeconômicas.

\section{ANÁLISE E DISCUSSÃO DOS RESULTADOS}

Esta seção apresentará as duas etapas detalhadas nos procedimentos metodológicos. A primeira etapa considera os cinco alimentos que registraram as maiores altas de preço no primeiro semestre de 2013, de acordo com o IPCA/IBGE. A segunda contempla a análise dos dados cedidos pela empresa Kantar Worldpanel (informação pessoal), que contêm as variações percentuais em volume de consumo de categorias relativas às cestas de alimentos analisadas pela referida empresa no primeiro semestre de 2013 em relação ao primeiro semestre de 2012 .

\subsection{A dinâmica dos cinco produtos olerícolas mais impactados pela inflação}

Considerando a primeira etapa de análise da pesquisa, tem-se que, no mês de janeiro de 2013, o IPCA apresentou a maior variação percentual desde abril de 2005, ou seja, 0,86\%. Para tanto, os preços do grupo de alimentos e bebidas compreendeu a variação mensal de 1,99\%, correspondendo a 56\% do IPCA. Nesse mês, os produtos alimentares sofreram aumento nos preços, principalmente em razão de problemas climáticos que interferiram na colheita de determinados produtos agrícolas, diminuindo, desse modo, a sua oferta, como, por exemplo, o tomate (variação de 26,15\%) e a batata inglesa (20,58\%) (IBGE, 2013a).

Em fevereiro de 2013, a variação do IPCA registrou 0,60\%; para o mesmo período, em 2012, o valor foi de $0,45 \%$. 0 mês de fevereiro demonstrou uma variação menor na mensuração da inflação, o que pode

\footnotetext{
${ }^{9}$ ANDRADE, Carolina. Variação de consumo na cesta de alimentos nas classes socioeconômicas: Kantar Worldpanel Brasil. Mensagem recebida por < drkawano@gmail.com> em: 12 ago. 2013.

${ }^{10}$ Exceto para as cidades da região Norte do país, em que a cobertura contempla cidades com mais de duzentos mil habitantes.
} 
ser explicado em sua maior parte pela redução no valor da energia elétrica. Observa-se que, para o grupo de alimentos e bebidas, houve uma diminuição na variação, registrando 1,45\% e respondendo por $58 \%$ do IPCA do referido mês. Assim sendo, destaca-se o tomate (20,17\%), cujo aumento foi significativo, resultado mais uma vez de problemas climáticos em sua produção (IBGE, 2013b).

0 período de referência do IPCA de março registrou uma variação de $0,47 \%$, a redução foi devida, principalmente, pela queda nos valores da educação. Nesse momento, o grupo de alimentos e bebidas também diminuiu de 1,45\% para 1,14\% (ou seja, 60\% do IPCA de março) (IBGE, 2013c). Em abril de 2013, o IPCA variou no período de análise em $0,55 \%$, o que considerou um aumento no preço dos remédios (elevação de 2,99\%). Nesse mês, os preços do grupo de alimentos e bebidas continuaram a desacelerar relativamente ao que se constatou nos meses anteriores. Entretanto, esses produtos representaram 44\% do IPCA de abril. Cumpre destacar o aumento de $0,92 \%$ das refeições feitas fora do domicílio (IBGE, 2013d).

0 mês de maio de 2013 registrou uma variação de 0,37\% em relação ao período de referência do IPCA, novamente o índice teve a contribuição dos preços dos remédios. Em um contexto geral, houve a desaceleração nos preços de alguns alimentos mensurados como, por exemplo, o tomate $(-10,31 \%)$ (IBGE, 2013e). O IPCA de junho de 2013 registrou uma variação de 0,26\%, permanecendo a retração do grupo de alimentos e bebidas, isto é, de 0,31\% (maio) para 0,04\% (IBGE, 2013f).

Considerando o período de junho de 2012 a junho de 2013, o IPCA registrou uma variação percentual de 6,70\%; já para os seis primeiros meses de 2012, o mesmo índice registrou um aumento de 3,15\%. Os grupos que mais contribuíram para o aumento dos preços analisados pelo IPCA foram (sendo o primeiro valor correspondente à variação percentual de junho de 2012 a junho de 2013 e o segundo valor equivalente à variação do primeiro semestre de 2013$)$ : alimentos e bebidas $(12,80 \% ; 6,02 \%)$, despesas pessoais $(8,69 \%$; $4,13 \%)$, educação (7,82\%; 6,73\%), saúde e cuidados pessoais (6,90\%; 4,36\%) (IBGE, 2013f).

No acumulado do primeiro semestre de 2013, observou-se que o grupo de alimentos e bebidas (Quadro 1) foi o que mais elevou a variação percentual do IPCA no período considerado. Dessa forma, elencou-se a análise dos cinco principais produtos que tiveram as maiores variações percentuais no período em questão: batata inglesa $(67,84 \%)$, cebola $(58,88 \%)$, cenoura $(44,52 \%)$, tomate $(43,80 \%)$ e feijão carioca $(41,01 \%)$.

As variações percentuais dos cinco produtos destacados de janeiro a junho de 2013 estão dispostas na Tabela 1, bem como os índices do IPCA, do seu valor correspondente em 2012 e do grupo de alimentos e bebidas.

Tabela 1 - IPCA dos cinco alimentos que acumularam a maior variação percentual

\begin{tabular}{|c|c|c|c|c|c|c|c|c|}
\hline IPCA & IPCA(\%) & IPCA2012(\%) & $\begin{array}{l}\text { Alimentos e } \\
\text { bebidas (\%) }\end{array}$ & $\begin{array}{l}\text { Batata inglesa } \\
(\%)\end{array}$ & Cebola (\%) & Cenoura (\%) & $\begin{array}{l}\text { Feijão carioca } \\
(\%)\end{array}$ & Tomate (\%) \\
\hline Janeiro & 0,86 & 0,56 & 1,99 & 20,58 & 14,25 & 9,83 & 5,27 & 26,15 \\
\hline Fevereiro & 0,60 & 0,45 & 1,45 & 7,90 & 11,64 & 21,41 & 6,99 & 20,17 \\
\hline Março & 0,47 & 0,21 & 1,14 & 6,14 & 21,43 & 14,96 & 9,08 & 6,14 \\
\hline Abril & 0,55 & 0,64 & 0,96 & 16,16 & 10,96 & 7,82 & 9,44 & 7,39 \\
\hline Maio & 0,37 & 0,36 & 0,31 & 3,55 & $-2,69$ & 7,33 & 7,23 & $-10,31$ \\
\hline Junho & 0,26 & 0,08 & 0,04 & 1,04 & $-4,99$ & $-18,53$ & $-2,19$ & $-7,21$ \\
\hline
\end{tabular}

Fonte: Elaborada pelos autores com base em IBGE (2013)

Com base na Tabela 1, verifica-se que a batata inglesa apresentou a maior alta em janeiro de 2013 $(20,58 \%)$, tendo uma retração mais expressiva a partir do mês de maio (3,55\%). 0 valor percentual acumulado no preço do tubérculo no primeiro semestre foi de 67,84\%. 0 valor mais alto pago pelo consumidor final foi reflexo de problemas na oferta do produto, podendo-se mencionar a questão dos fatores climáticos, bem como o aumento dos preços dos insumos necessários para a sua produção. Verificou-se que a chuva em excesso em estados, como Paraná, São Paulo e Goiás, acarretou um atraso na colheita da batata inglesa, a qual se intensificou a partir de maio. A safra 2012/2013 caracterizou-se pela diminuição da produtividade, muito em decorrência das chuvas (principalmente, nos meses de março e abril), e da área plantada em determinados locais, como por exemplo, na Chapada Diamantina no estado da Bahia, elucidada também pela seca presente na região Nordeste (RAMOS et al., 2013).

Confere-se à cebola a variação percentual acumulada do IPCA de 58,88\% nos seis primeiros meses de 2013. Por um lado, o mês que obteve a maior alta foi março $(21,43 \%)$; de outro lado, destaca-se a queda dos preços registrados nos meses de maio $(-2,69 \%)$ e junho $(-4,99 \%)$. Para o caso da cebola, uma baixa oferta foi verificada no país nos meses analisados, o que implicou necessariamente o aumento dos preços. 
A retração da oferta pode ser discutida por alguns fatores, como a seca no Nordeste, as precipitações que geraram adversidades durante o seu plantio no Cerrado entre os meses de fevereiro e março, entre outros. Esse cenário suscitou a necessidade de se importar o produto da Argentina, Holanda e Chile, o que exigiu a elevação do preço pago pelo consumidor final em momentos específicos. A esperada safra de março de 2013 no estado de São Paulo corroborou com a queda nos preços dos meses subsequentes e, em julho, houve a intensificação da colheita do produto em diversas regiões do país (PALHARES; DELEO; SABIO, 2013).

A cenoura apresentou o terceiro maior percentual acumulado, ou seja, 44,52\% nos seis primeiros meses de 2013 . 0 mês de fevereiro destacou o maior percentual $(21,41 \%)$, havendo uma desaceleração nos preços em junho $(-18,53 \%)$. A justificativa em torno do segundo percentual decorre dos bons resultados na safra de verão. As chuvas nos primeiros meses de análise, as adversidades da etapa de pós-colheita e a ocorrência de doenças tidas no campo desencadearam a retração da oferta nos meses de março e abril de 2013. A seca justificou a redução na oferta do produto, principalmente, no estado da Bahia. Alguns estados, como o Rio Grande do Sul, por exemplo, apresentaram condições climáticas adequadas para a produção da raiz no mês de junho de 2013, o que ajuda a elucidar a queda nos preços registrados pelo IPCA no mês em questão (DUMBRA; VENTURA; SABIO, 2013).

Por sua vez, o tomate teve uma variação percentual acumulada de 43,80\% no primeiro semestre de 2013. Nos meses de janeiro e fevereiro, a fruta apresentou os maiores percentuais do período analisado, $26,15 \%$ e 20,17\%, respectivamente; o inverso foi observado nos meses de maio e junho, em que houve queda de 10,31\% e 7,21\%, nessa ordem. Por exemplo, a cidade de Sumaré/SP e a região norte do estado do Paraná não apresentaram uma produtividade boa no início do ano, pois houve a ocorrência da mosca branca e bacterioses, o que causou a diminuição da oferta do produto. Destaca-se igualmente a redução da área destinada à safra de verão 2012/2013 e dos investimentos agrícolas para tal atividade, espera-se uma diminuição da produção para a safra de inverno, mas com boas perspectivas de rendimento (ZAGALI et al., 2013).

O Brasil configura-se como o principal produtor de feijão em nível mundial, com aproximadamente 3,5 milhões de toneladas (MAPA, 2013). Sinaliza-se um aquecimento do consumo de feijão, considerando um crescimento de 1,22\% ao ano de 2009/2010 a 2019/2020 (MAPA, 2013). 0 feijão carioca obteve a quinta posição no que tange à variação percentual do primeiro semestre de 2013, ou seja, um IPCA acumulado de 41,01\%, sendo sua elevação mais expressiva em abril $(9,44 \%)$ e obtendo uma retração de 2,19\% em junho. Para o feijão comum carioca, os estados que têm expressividade na oferta do produto são Minas Gerais, São Paulo e Goiás (CONAB, 2013). Atividades agrícolas mais rentáveis, como a soja e o milho, fizeram com que produtores migrassem da produção de feijão para a das commodities mencionadas, os fatores climáticos também responderam pela diminuição da oferta do mencionado produto.

Gráfico 1 - Variação dos alimentos que acumularam maior variação percentual

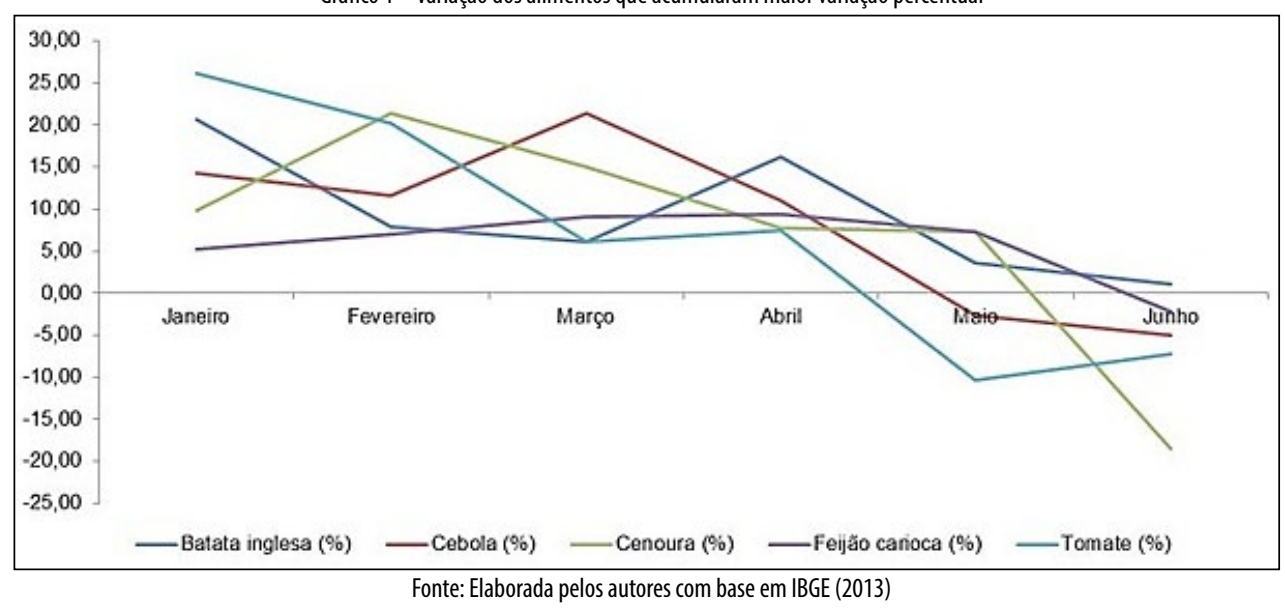

Com base nos dados analisados na Tabela 1 e no Gráfico 1 dos cinco alimentos enfatizados, em suma, na relação entre preço e quantidade ofertada, sabe-se que, em épocas de safra de produtos agrícolas, a tendência é uma retração dos preços dada a maior quantidade dos produtos à disposição para o consumo. Em contrapartida, na maioria dos casos, há uma redução na oferta desses produtos no momento em que ocorrem problemas climáticos, o que converge para a elevação dos preços finais deles. Como são considerados produtos básicos da alimentação da população brasileira, a alta dos preços mensurada 
pelo IPCA leva os consumidores a realizarem pesquisas de preços no varejo supermercadista e nas feiras de hortifrutigranjeiros, a fim de propiciar um melhor custo-benefício ao considerarem suas restrições orçamentárias em virtude da redução de seu poder de compra; muitas vezes, incorre-se na redução da quantidade consumida de alguns alimentos ou na substituição por outros alimentos que apresentem funcionalidades semelhantes.

\subsection{As dez categorias de alimentos industrializados com maior retração em volume consumido}

Como destacado na parte inicial deste trabalho, esta segunda etapa do artigo é dedicada a apresentar os alimentos industrializados que tiveram maior queda de consumo em volume (em termos percentuais) no primeiro semestre de 2013, na comparação com o mesmo período do ano anterior. Além disso, são evidenciadas também as variações dentro das classes socioeconômicas, nos segmentos $\mathrm{AB}, \mathrm{C}$ e $\mathrm{DE}$. Como se verá mais adiante, tais dados ajudarão a explicar com maior precisão a dinâmica dessas categorias, uma vez que nem sempre os resultados negativos para a categoria na sua totalidade são verificados em todas as classes que as consomem, desempenho que pode variar igualmente em razão de outros fatores que procuramos apontar na discussão dos resultados. A lista com as categorias pode ser vista na Tabela 2.

Tabela 2 - Variação em volume de alimentos industrializados

\begin{tabular}{|c|c|c|c|c|}
\hline \multirow[b]{2}{*}{ Categoria } & \multicolumn{4}{|c|}{ Retração em volume (\%) } \\
\hline & Total & Classes AB & Classe C & Classes DE \\
\hline Polpa e purê de tomate & $-19,3$ & $-24,5$ & $-23,7$ & $-3,4$ \\
\hline Leite em pó & $-15,7$ & $-5,1$ & $-9,4$ & $-24,5$ \\
\hline Prato pronto congelado & $-13,6$ & $-10,6$ & $-11,0$ & $-17,5$ \\
\hline Bebida à base de soja & $-13,2$ & $-19,6$ & $-9,0$ & $-3,3$ \\
\hline Batata congelada & $-7,6$ & $-12,1$ & $-3,0$ & $-0,4$ \\
\hline Cereal tradicional & $-6,7$ & $-2,9$ & 1,9 & $-15,0$ \\
\hline Massa instantânea & $-5,1$ & $-8,9$ & $-3,8$ & 0,1 \\
\hline Sobremesa em pó & $-3,1$ & 2,2 & $-3,8$ & $-12,8$ \\
\hline Suco concentrado & $-2,3$ & 4,9 & $-19,5$ & 20,3 \\
\hline Hambúrguer & $-2,2$ & $-1,3$ & $-4,6$ & 0,7 \\
\hline
\end{tabular}

Fonte: Dados da pesquisa (2013)

Como se pode notar, quatro das dez categorias sofreram uma retração superior a 10,0\% em seus respectivos volumes, sendo as polpas e purê de tomate os produtos mais afetados, especialmente nas classes média e alta, grupos nos quais a retração foi superior à média da categoria. De forma semelhante, constata-se uma variação em pratos prontos congelados, bebidas à base de soja, batata congelada e massas instantâneas.

Por outro lado, o leite em pó teve sua maior queda de consumo verificada nas classes D e E (redução de $24,5 \%)$. Esse mesmo cenário pode ser notado também nas categorias de pratos prontos congelados, cereais tradicionais, sobremesas em pó e sucos concentrados, indicando, portanto, um comportamento distinto, o qual se altera conforme os segmentos aos quais os compradores pertencem. Os fatores para tais mudanças, contudo, podem variar nas categorias, aspecto que será abordado na subseção seguinte.

\subsubsection{Análise e discussão dos resultados: razões para a retração nas categorias}

Uma razão possível para a queda no consumo das polpas e purê de tomate poderia ser, a priori, o aumento do preço do tomate verificado no primeiro semestre de 2013, como foi discutido na primeira parte do artigo. Entretanto, uma análise mais atenta permite mostrar que um fator mais forte sugere estar associado à mencionada queda: a busca por produtos com maior valor agregado. De fato, se por um lado as polpas e purê retraíram 19,0\%, a categoria de molhos prontos para o consumo apresentou alta de 11,2\%, valor que se mantém próximo desse nível (10,3\%) para as classes $A B$, justamente onde as retrações em polpa foram maiores, indicando, portanto, uma migração para produtos mais caros, mas com um maior 
apelo à praticidade.

Já na categoria de leite em pó, o que se verifica é uma maior retração nas classes mais baixas. Esse aspecto é especialmente importante na medida em que foram justamente as classes mais baixas que passaram a adotar o leite em pó em 2010 (ANDRADE, 2013), momento em que a situação econômica do país era mais favorável. Contudo, diante dos aumentos consecutivos no preço dos alimentos e bebidas, essas classes não conseguiram manter o mesmo padrão de consumo, forçando-as a abandonar ou reduzir a compra de leite em pó. 0 principal motivo para a redução no consumo do leite em pó foi, por conseguinte, a alta de preço, que atingiu 12,41\% no semestre em questão e quase 19,0\% de julho de 2012 a junho de 2013 , segundo o IBGE, por causa da baixa oferta de leite, somada à elevada demanda por parte das indústrias de laticínios, como aponta o Centro de Estudos Avançados em Economia Aplicada (CEPEA, 2013a) da Esalq/USP. Segundo o mesmo centro de pesquisa, o preço bruto do leite pago ao produtor (incluindo frete e impostos) alcançou, em julho de 2013, R \$1,0544/litro, maior valor dos últimos seis anos. Em termos regionais e de produção, a região Sul destaca-se, com a baixa produção ocasionada pela falta de chuvas entre abril e maio, prejudicando, desse modo, a semeadura das pastagens de inverno na região, além da escassez de alimentos para as vacas, também em maio de 2013.

Já o consumo dos pratos prontos congelados parece estar ligado às mudanças sociais e de sua relação com o comportamento do consumidor: fatores como o aumento do percentual de pessoas que moram sozinhas, inserção da mulher no mercado de trabalho e crescimento do poder de compra dos brasileiros tornam salientes os aspectos de compra associados à maior praticidade, rapidez e comodidade. Entretanto, a categoria foi afetada pelo aumento dos preços ligados à sua produção. 0 preço do trigo, que está fortemente atrelado às massas congeladas, sofreu um aumento nos preços de 43,5\% em 2013 em relação a 2012, segundo a Associação Brasileira da Indústria de Trigo (ABITRIGO, 2014), com a tonelada atingindo o valor de $\mathrm{R} \$ 772$. De acordo com a referida instituição, o aumento foi repassado para toda a cadeia, nos preços da farinha de trigo e dos outros derivados, como os produtos industrializados. 0 mesmo cenário ajuda a explicar igualmente a retração na categoria de massas instantâneas.

Assim como no caso dos molhos prontos para o consumo, a categoria de bebidas à base de soja (BBS) está relacionada ao aumento do poder de compra da população, que tem gerado, como consequência, uma busca por maior praticidade, com bebidas prontas para o consumo. É, por conseguinte, uma categoria em expansão, que entre 2005 e 2011 ganhou dez milhões de novos lares consumidores (ABRAS, 2011). Apesar disso, a movimentação dissonante dos dados anteriores parece estar ligada a um aspecto pontual: um problema na linha de produção de um importante fabricante que atua no setor obrigou a empresa a suspender a comercialização de seus produtos por quase três semanas (entre março e abril de 2013). Tal fato pode ressoar não somente no consumo da marca afetada, mas também no de seus concorrentes, uma vez que o consumidor pode ser impactado pela percepção negativa associada a um atributo importante do processo de decisão de compra (SOLOMON, 2008). De fato, um processo semelhante já ocorreu também no mercado de bebidas, quando uma marca de água, pertencente a uma grande indústria de alimentos em termos mundiais, notou problemas de contaminação por benzeno no produto, repercussão que impactou toda a categoria naquele mercado (PEREIRA, 1990).

No que tange ao segmento de batatas congeladas, o principal fator que contribuiu para a redução no consumo desses produtos foi a alta do preço da batata, o qual registrou um aumento de $67,84 \%$ no primeiro semestre de 2013, segundo dados do IBGE. Em relação a 2012, de acordo com o IBGE, houve um aumento dos custos de produção da batata, gerando uma menor área plantada com redução de 9,0\% relativamente a 2011. Outro aspecto importante a ser mencionado é que $72,0 \%$ de toda a batata congelada no Brasil é importada, de modo que alterações no mercado de câmbio (a valorização do dólar em relação ao real) atuaram diretamente no preço do produto final no Brasil.

Também impactada pelo preço, a queda de 6,7\% dos cereais tradicionais pode ser explicada pelo aumento do preço da principal matéria-prima envolvida na sua produção, a aveia. Segundo levantamento da Agência Agrolink (2013), a cotação da aveia (R\$ por saca de 60 quilos) aumentou consideravelmente a partir de 2012 (Figura 2), elevação que resultou no produto final. 
Figura 2 - Cotação do preço da aveia (R\$/saca 60 quilos) - janeiro de 2012 a julho de 2013

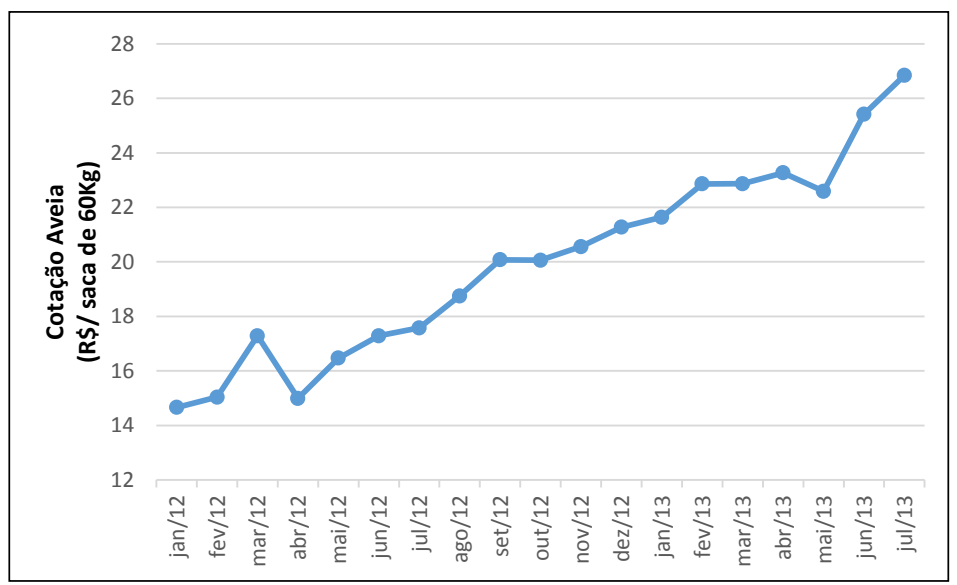

Fonte: Elaborada pelos autores com base em Agência Agrolink (2013)

No que se refere às sobremesas em pó, constata-se que a retração da categoria não se deu de maneira uniforme entre as classes socioeconômicas, mas sim apresentando uma grande retração nas classes D e E. Nessa direção, na medida em que enquadramos o segmento de sobremesas como uma categoria não básica, podemos notar que, em momentos de restrição orçamentária, essa faixa dos consumidores é a primeira a reduzir a compra desses produtos, ao sofrer mais com o processo inflacionário.

A queda no consumo da nona categoria com maior queda, a dos sucos concentrados, precisa ser enquadrada no contexto da cesta de bebidas. A exemplo do que foi discutido em bebidas à base de soja, as famílias brasileiras têm sofisticado seu consumo em virtude do aumento do poder de compra. Com isso, podem-se observar, ao longo dos últimos anos, dois processos que ajudam a elucidar a retração dos sucos prontos: a ampliação da cesta de bebidas e a busca por praticidade e produtos com maior valor agregado.

Já em 2009, os sucos concentrados estavam entre os cinco produtos que mais apresentavam queda, juntamente com a categoria de polpa e purê de tomate (produto também com menor valor agregado, se comparado aos molhos prontos). Dados da Associação Brasileira das Indústrias de Refrigerantes e de Bebidas Não Alcoólicas (ABIR, 2012) mostram que, em 2010, os sucos concentrados ocuparam a última posição em crescimento dentre as demais categorias da cesta de bebidas, com crescimento de apenas $2,3 \%$ naquele ano.

Tal evolução no consumo do mercado pode, por fim, ser discutido em razão do desempenho da categoria nas classes socioeconômicas. A classe $\mathrm{C}$, na qual o consumo de sucos prontos para beber cresceu mais de $34,0 \%$ no primeiro semestre de 2013, foi justamente a que impulsionou a queda no consumo de sucos concentrados, tendo ocorrido, nesse segmento, queda de 19,5\%, sinalizando uma migração no consumo desses produtos para os de maior praticidade (sucos prontos). Nas classes DE, por outro lado, o custo-benefício dos sucos concentrados atua como um importante atributo, fazendo com que o segmento crescesse $20,3 \%$.

Por fim, a categoria de hambúrgueres possui destaque entre os alimentos congelados, pois é considerada uma categoria de entrada para outros alimentos do segmento. Sua presença nos lares brasileiros é expressiva, sendo a classe $C$ a que mais contribuiu para a retração, com queda de $4,6 \%$ no consumo (versus queda de 2,2\% no total da categoria). Nesse sentido, um destaque da conjuntura de mercado que merece ser destacado, e que pode ter contribuído para essa redução, foi a questão envolvendo a presença de carne de cavalo misturada à carne bovina em hambúrgueres de importantes redes de alimentação da Europa, cujo fato foi amplamente veiculado nos meios de comunicação de massa.

Com base nessas considerações, pode-se notar que diferentes aspectos estiveram relacionados às movimentações de volume nas categorias, cujos destaques estão sintetizados na Tabela 3. 
Tabela 3 - Fatores de influência sobre redução de consumo dos alimentos industrializados

\begin{tabular}{|c|c|c|}
\hline Categoria & $\begin{array}{l}\text { Fatores que influenciaram na retração da categoria (volume } \\
\qquad \% \text { de vendas) }\end{array}$ & $\begin{array}{l}\text { Classes socioeconômicas com } \\
\text { maior redução no consumo }\end{array}$ \\
\hline Polpa e purê de tomate & $\begin{array}{l}\text { Substituição por produtos com maior valor agregado e apelo à } \\
\text { praticidade. Ex.: molhos prontos. }\end{array}$ & $A B$ e $C$ \\
\hline Leite em pó & Baixa oferta de leite somada à falta de chuvas na região Sul do país. & $\mathrm{DE}$ \\
\hline Prato pronto congelado & Aumento do preço de matérias-primas: trigo e molhos para massas. & $\mathrm{DE}$ \\
\hline Bebida à base de soja & Restrições de comercialização de uma marca no segmento. & $A B$ \\
\hline Batata congelada & $\begin{array}{l}\text { Alta do preço do produto tanto internamente comó na importaçãa } \\
\text { (desvalorizaçąa do real perante o dólar). }\end{array}$ & $A B$ \\
\hline Cereal tradicional & Aumento do preço de matérias-primas: aveia. & $\mathrm{DE}$ \\
\hline Massa instantânea & Aumento do preço de matérias-primas: trigo. & $A B$ \\
\hline Sobremesa em pó & $\begin{array}{l}\text { Redução do consumo de alimentos não básicos pelas classes mais } \\
\text { baixas, causada pela inflação. }\end{array}$ & $\mathrm{DE}$ \\
\hline Suco concentrado & $\begin{array}{l}\text { Substituição por produtos com maior valor agregado e apelo à } \\
\text { praticidade. Ex.: sucos prontos. }\end{array}$ & C \\
\hline Hambúrguer & $\begin{array}{l}\text { Redução do consumo de alimentos não básicos pela classe C, causada } \\
\text { pela inflação. }\end{array}$ & C \\
\hline
\end{tabular}

Fonte: Elaborada pelos autores (2014)

\subsection{Comparação dos resultados à literatura}

Nesta seção, comparam-se os principais resultados do trabalho com os presentes na literatura citada na seção 2. Visualiza-se em FGV (2008) e FAO (2008) que a discussão em torno da inflação dos alimentos tem uma abordagem global, tendo como variáveis explicativas para o aumento do preço dos alimentos elementos como: rápido crescimento populacional e da economia em muitos países emergentes; aumento do preço do petróleo, bem como a utilização de cereais e de outros produtos agrícolas na fabricação de combustíveis. No presente trabalho, essas questões não são as principais variáveis explicativas para o aumento dos preços dos alimentos analisados, e, sim fatores climáticos, assim como a maior demanda em virtude da renda ou mudanças de hábitos dos consumidores.

Isso se deve à maioria dos alimentos analisados apresentarem mercados domésticos. Alguns trabalhos, como FAO (2008), reforçam que os preços internacionais não são totalmente refletidos nos preços domésticos, e as mudanças nos preços domésticos, muitas vezes, não são necessariamente causadas por eventos nos mercados internacionais. Esse é um dos principais pontos do trabalho, alguns produtos analisados, como cenoura, cebola e tomate, por exemplo, apresentam mercados nacionais, não estando integrados em mercados internacionais como milho e soja.

Em trabalho realizado por Hoyos e Medvedev (2009), analisando o preço internacional e preço doméstico em países em desenvolvimento de alimentos no período de 2005 a 2007, constata-se que os preços domésticos dos alimentos cresceram $5,6 \%$, bem abaixo dos $31 \%$ dos preços internacionais. Os autores justificam esse fato em razão de os preços domésticos dependerem mais de fatores como o desempenho da produção local (impactado por fatores climáticos), como visualizado em parte dos alimentos analisados, de tributos e custos de transportes, do que dos preços internacionais.

Outro elemento importante visualizado no trabalho refere-se à renda. Na literatura já está consolidado (AZEVEDO, 2010) que, em países onde a renda per capita é baixa e a distribuição de renda é concentrada, caso do Brasil, os produtos agroindustriais apresentam maior elasticidade do preço da demanda que em países com maior renda per capita. Isso ficou evidenciado na retração de consumo de alguns produtos, como prato pronto congelado nas classes D e E, onde ocorreu um aumento no preço do produto em virtude do aumento das matérias-primas com molhos e farinhas. 0 trabalho corrobora com a afirmação de NEPA (2009) que afirma que os extratos de pessoas com renda menor estão mais sujeitos a sofrer as consequências negativas de aumento de preço de alimentos.

$\mathrm{Na}$ literatura, encontram-se trabalhos analisando aumento de preço em cereais, grãos, leite e carne; entretanto, produtos alimentícios processados e vegetais são escassos na literatura. O presente trabalho avança analisando quinze produtos alimentícios, principalmente vegetais e produtos alimentícios processados de forma individual. De acordo com Martinez e Cerqueira (2011), muito da dinâmica por trás 
do fenômeno inflacionário perde-se com a agregação, uma vez que os preços dos bens têm comportamentos específicos que podem ser muito discrepantes entre si.

Os resultados do trabalho foram semelhantes aos encontrados por Martinez e Cerqueira (2013), e Maluf e Speranza (2013). Os resultados dos referidos autores indicaram igualmente que aumentos nos níveis de preços dos alimentos contribuíram para o aumento da inflação no país nos períodos analisados e, dessa forma, influenciaram a redução do consumo de alimentos, principalmente por famílias pertencentes às camadas socioeconômicas com menores índices de renda, como encontrado no trabalho para leite em pó, prato pronto congelado, cereal tradicional e sobremesa em pó.

\section{CONSIDERAÇÕES FINAIS}

O objetivo do trabalho foi o de identificar os vegetais que apresentaram maior inflação acumulada no primeiro semestre de 2013, assim como apontar as dez categorias de alimentos industrializados que sofreram maior retração de consumo no mesmo período, buscando, para cada um dos produtos, identificar e discutir as principais razões para o cenário negativo abordado ao longo deste trabalho. Nessa direção, foi possível elencar variáveis explicativas para o aumento do preço e redução do consumo nos quinze produtos analisados, sendo três as mais presentes na maioria dos produtos analisados para aumento dos preços e redução do consumo: fatores climáticos, renda e mudanças de hábitos de consumo.

0 trabalho avançou mostrando que a retração no consumo de alimentos processados não ocorreu de forma homogênea entre as diferentes classes socioeconômicas, mas sim impactando ora os segmentos de maior poder aquisitivo, nomeadamente as classes socioeconômicas A e B (como no caso das categorias de bebida à base de soja e polpa/purê de tomate), ora a parcela com menor poder de compra, para o caso de pratos prontos congelados e sobremesas em pó, aspectos que perpassam a busca por produtos com maior apelo à praticidade e maior valor agregado e pela maior fragilidade de se manter determinadas categorias na cesta de alimentos em momentos de maior restrição orçamentária. Logo, recomenda-se para estudos de tal natureza, sempre que possível, trabalhar com estratificação da amostra por renda.

A principal limitação do trabalho é em relação ao período da análise - realizada em apenas um semestre de 2013 -, não apresentando uma série temporal. Uma limitação secundária é que as dez categorias de alimentos e bebidas analisadas no trabalho não abrangem as compras que são seguidas de um consumo fora dos domicílios, por exemplo, bebidas consumidas em restaurantes e lanchonetes.

Para trabalhos futuros, seria oportuno visualizar o comportamento desses alimentos ao longo de uma série histórica e inserir novas variáveis, como preço de fertilizantes, petróleo, variação cambial, entre outras, analisando de forma quantitativa os dados e o reflexo no preço desses alimentos. Ressalta-se que, para alimentos processados, essa é uma análise complexa, pois a matéria-prima de origem vegetal ou animal, muitas vezes, representa uma pequena parcela do custo total do produto, sendo difícil encontrar associações entre as variáveis.

\section{AGRADECIMENTOS}

Diante do conteúdo apresentado e analisado, os autores do trabalho agradecem a Kantar Worldpanel Brasil pelo fornecimento exclusivo dos dados relativos à variação de volume nas categorias e classes socioeconômicas de alimentos e bebidas, os quais viabilizaram a realização deste estudo. Além disso, agradecemos à CAPES e ao CNPq pelo auxílio financeiro. 


\title{
THE INFLATIONARY PROCESS AND THE DYNAMICS OF FOOD CONSUMPTION IN BRAZIL: ECONOMIC, CLIMATIC AND CONSUMER BEHAVIOR ASPECTS
}

\begin{abstract}
With the intensification of competition, technologies related to market intelligence and its processes have become essential for companies to remain in the market, for example, through continuous information about inflation and customer shopping behavior. This paper aims to identify the factors that most influenced the increase in price of the five vegetables that had higher inflation rates in the first half of 2013. It also presents the ten categories of processed food with highest decrease in volume consumed, listing possible factors for the negative performance of these products. For this purpose, explanatory research of a quantitative nature was carried out using data from the National Index of Price to the Ample Consumer and information from a consumption panel of 8,200 Brazilian households. As main result, we observed that the decline in consumption of certain items did not occur homogeneously in different socioeconomic classes. It varied depending on specifics in each group. As a conclusion, it was found that other factors, besides the price increase, played an important role in the reduction of consumption, such as changes linked to the demand for products with higher added value and convenience.
\end{abstract}

Keywords: Market research. Consumer behavior. Inflation. Food retail.

\section{REFERÊNCIAS}

ASSOCIAÇÃO BRASILEIRA DAS INDÚSTRIAS DE REFRIGERANTES E DE BEBIDAS NÃO ALCOÓLICAS (ABIR). BNA Brasil Relatório 2011: ABIR consumo de todas as bebidas comerciais 2005-2010. [2012]. Disponível em: <http://www.abir.org.br/wp-content/uploads/downloads/ 2012/07/Relatorio-ABIR-2011.pptx>. Acesso em: 12 ago. 2013.

ASSOCIAÇÃO BRASILEIRA DA INDÚSTRIA DE TRIGO (ABITRIGO). Previsão de novas altas para derivados do trigo. [2014]. Disponível em: <http://www.aviculturaindustrial.com.br/noticia/previsaode-novas-altas-para-derivados-do-trigo/20140109093526_D_905>. Acesso em: 15 fev. 2014.

ASSOCIAÇÃO BRASILEIRA DE SUPERMERCADOS (ABRAS). Café da manhã do brasileiro fica mais encorpado. [2011]. Disponível em: <http://www.abras.com.br/superhiper/superhiper/ultima-edicao/ destaque/?materia=1713>. Acesso em: 15 mar. 2014.

ANDRADE, Carolina. Variação de consumo na cesta de alimentos nas classes socioeconômicas: Kantar Worldpanel Brasil. [Mensagem pessoal]. Mensagem recebida por <drkawano@gmail.com> em: 12 ago. 2013.

AGÊNCIA AGROLINK. Cotação do preço da aveia. [2013]. Disponível em: <http://www.agrolink.com.br/ cotacoes/Historico.aspx?e=9839\&p=3431\&l=13409>. Acesso em: 15 ago. 2013.

ARBAGE, A. P. Fundamentos de economia rural. Chapecó: Argos, 2006.

AZEVEDO, P. F. Comercialização de produtos agroindustriais. In: BATALHA, M. O. (Org.). Gestão agroindustrial. v. 1. São Paulo: Atlas, 2010. p. 63-112.

CENTRO DE ESTUDOS AVANÇADOS EM ECONOMIA APLICADA (CEPEA). Análise do mês: leite. [2013a]. Disponível em: <http://www.cepea.esalq.usp.br/leite/

?page $=164>$. Acesso em: 18 ago. 2013.

CENTRO DE ESTUDOS AVANÇADOS EM ECONOMIA APLICADA (CEPEA). Séries mensais da laranja. [2013b]. Disponível em: <http://cepea.esalq.usp.br/citros/?page=707>. Acesso em: 18 ago. 2013. 
COMPANHIA NACIONAL DE ABASTECIMENTO (CONAB). Conjuntura semana: feijão - período 05 a 09.08.2013. [2013]. Disponível em: <http://www.conab.gov.br/OlalaCMS//uploads/arquivos/ 13_08_13_17_45_35_conjunturafeijao05a09082013.pdf>. Acesso em: 22 ago. 2013.

DUMBRA, J. G. R; VENTURA, M. B.; SABIO, R. P. Cenoura. Hortifruti Brasil, São Paulo, v. 12, n. 123, p. 34, maio 2013. Disponível em: <http://cepea.esalq.usp.br/hfbrasil/>. Acesso em: 12 ago. 2013.

FOOD AND AGRICULTURE ORGANIZATION (FAO). Soaring Food Prices: Facts, Perspectives, Impacts and Actions Required. [2008]. Disponível em: <http://www.fao.org/fileadmin/user_upload/foodclimate/ HLCdocs/HLC08-inf-1-E.pdf>. Acesso em: 6 abr. 2014.

FUNDAÇÃO GETULIO VARGAS (FGV). Fatores Determinantes dos Preços dos Alimentos 0 Impacto dos Biocombustíveis. Rio de Janeiro: FGV, 2008. Disponível em: <http://bibliotecadigital.fgv.br/dspace/ bitstream/handle/10438/6947/326.pdf?sequence=1>. Acesso em: 10 mar. 2014.

HOYOS, R. E. de; MEDVEDEV, D. Poverty effects of higher food prices: a global perspective. Washington, DC: World Bank, 2009.

INSTITUTO BRASILEIRO DE GEOGRAFIA E ESTATÍSTICA (IBGE). Índices Nacionais de Preços ao Consumidor: IPCA e INPC, janeiro 2013. [2013a]. Disponível em: <http://www.ibge.gov.br/home/ estatistica/indicadores/precos/inpc_ipca/ipca-inpc_201307comentarios.pdf >. Acesso em: 12 ago. 2013.

INSTITUTO BRASILEIRO DE GEOGRAFIA E ESTATÍSTICA (IBGE). Índices Nacionais de Preços ao Consumidor: IPCA e INPC, fevereiro 2013. [2013b]. Disponível em: <http://www.ibge.gov.br/home/ estatistica/indicadores/precos/inpc_ipca/ipca-inpc_201302comentarios.pdf>. Acesso em: 12 ago. 2013.

INSTITUTO BRASILEIRO DE GEOGRAFIA E ESTATÍSTICA (IBGE). Índices Nacionais de Preços ao Consumidor: IPCA e INPC, março 2013. [2013c]. Disponível em: <www.ibge.gov.br/home/estatistica/ indicadores/precos/inpc_ipca/ipca-inpc_201303comentarios.pdf>. Acesso em: 12 ago. 2013.

INSTITUTO BRASILEIRO DE GEOGRAFIA E ESTATÍSTICA (IBGE). Índices Nacionais de Preços ao Consumidor: IPCA e INPC, abril 2013. [2013d]. Disponível em: <www.ibge.gov.br/home/estatistica/ indicadores/precos/inpc_ipca/ipca-inpc_201304comentarios.pdf>. Acesso em: 12 ago. 2013.

INSTITUTO BRASILEIRO DE GEOGRAFIA E ESTATÍSTICA (IBGE). Índices Nacionais de Preços ao Consumidor: IPCA e INPC, maio 2013. [2013e]. Disponível em: <www.ibge.gov.br/home/estatistica/ indicadores/precos/inpc_ipca/ipca-inpc_201305comentarios.pdf>. Acesso em: 12 ago. 2013.

INSTITUTO BRASILEIRO DE GEOGRAFIA E ESTATÍSTICA (IBGE). Índices Nacionais de Preços ao Consumidor: IPCA e INPC, junho 2013. [2013f]. Disponível em: <www.ibge.gov.br/home/estatistica/ indicadores/precos/inpc_ipca/ipca-inpc_201305comentarios.pdf>. Acesso em: 12 ago. 2013.

KAHNEMAN, D. Pensar, depressa e devagar. Lisboa: Temas \& Debates, 2012.

MINISTÉRIO DA AGRICULTURA, PECUÁRIA E ABASTECIMENTO (MAPA). Feijão. [2013]. Disponível em: <http://www.agricultura.gov.br/vegetal/culturas/feijao>. Acesso em: 10 ago. 2013.

MALUF, R. S.; SPERANZA, J. Volatilidade dos preços internacionais e inflação de alimentos no Brasil: fatores determinantes e repercussões na segurança alimentar e nutricional. Brasília, DF: Câmara Interministerial de Segurança Alimentar e Nutricional (CAISAN), 2013.

MARTINEZ, T. S.; CERQUEIRA, V. dos S. Estrutura da inflação brasileira: determinantes e desagregação do IPCA. Texto para Discussão no 1634. Rio de Janeiro: IPEA, 2011.

MARTINEZ, T.; CERQUEIRA, V. dos S. Estrutura da inflação brasileira: determinantes e desagregação do IPCA. Econ. soc. [online],v. 22, n. 2, p. 409-456, 2013. 
MARTINS, G. A.; THEÓPHILO, C. R. Metodologia da investigação científica para ciências sociais aplicadas. 2. ed. São Paulo: Atlas, 2009.

NÚCLEO DE ESTUDOS E PESQUISAS EM ADMNISTRAÇÃO (NEPA). A crise mundial dos alimentos e a vulnerabilidade dos países periféricos. [2009]. Disponível em: <http://www.unicamp.br/nepa/ CriseAlimentosVersaofinal_17112009.pdf>. Acesso em: 11 mar. 2014.

PALHARES, I. de N.; DELEO, J. P. B.; SABIO, R. P. Cebola. Hortifruti Brasil, São Paulo, v. 12, n. 123, p. 28-28, maio 2013. Disponível em: <http://cepea.esalq.usp.br/hfbrasil/>. Acesso em: 12 ago. 2013.

PEREIRA, L. C. R. Generalidades sobre a responsabilidade civil do fabricante. Revista dos Tribunais, São Paulo, n. 654, p. 52-56, abr. 1990.

PINDYCK, R.; RUBINFELD, D. L. Microeconomia. São Paulo: Prentice Hall, 2010.

RAMOS, R. M. et al. Batata. Hortifruti Brasil, São Paulo, v. 12, n. 123, p. 33-33, maio 2013. Disponível em: <http://cepea.esalq.usp.br/hfbrasil/>. Acesso em: 12 ago. 2013.

SOLOMON, M. B. 0 comportamento do consumidor: comprando, possuindo e sendo. Porto Alegre: Artmed, 2008.

ZAGALI, F. Q. et al. Tomate. Hortifruti Brasil, São Paulo, v. 12, n. 123, p. 32-32, maio 2013. Disponível em: <http://cepea.esalq.usp.br/hfbrasil/>. Acesso em: 12 ago. 2013. 